\title{
Propuesta didáctica de interacción oral para estudiantes de ELE de nivel A1 en un entorno de enseñanza a distancia digital
}

PaUla NAVARro Brazales

Universitat de València

paunabra@alumni.uv.es

\begin{abstract}
Resumen: La interacción oral ha permanecido marginada en la enseñanza de lenguas a distancia, tanto en el aula como fuera de ella con tareas que consisten en ejercicios escritos. Presentamos una propuesta didáctica basada en la combinación del enfoque por tareas y del enfoque léxico para estudiantes de ELE de nivel A1, en un entorno de enseñanza a distancia digital, centrada en la interacción oral. Unimos sincronía y asincronía para proponer que es posible la práctica de esta destreza en cursos de ELE a distancia, tanto en tiempo real como con la asignación de tareas orales, como defiende Méndez García (2010), mediante cuatro herramientas tecnológicas: Zoom, Flipgrid, Voxopop y WhatsApp. El resultado es una secuencia didáctica en la que se trabajan unidades léxicas de los deportes y de la vida saludable a partir de cinco tipos de actividades, con las que desarrollar la competencia comunicativa, léxica y digital de los alumnos.
\end{abstract}

Palabras clave: Interacción oral, Español Lengua Extranjera, enseñanza a distancia digital, enfoque léxico, enfoque por tareas.

\section{Didactic Proposal of oral interaction for A1 level SFL students in a digital distance learning environment}

Abstract: Oral interaction has remained marginalized in distance language learning, both in the classroom and outside of it with tasks consisting of written exercises. We present a didactic proposal based on the combination of the task-based approach and the lexical approach for A1 level SFL students, in a digital distance learning environment, focused on oral interaction. We unite synchrony and asynchrony to propose that it is possible to practice this skill in distance SFL courses, both in real time and with the assignment of oral tasks, as Méndez García (2010) defends, through four technological tools: Zoom, Flipgrid, Voxopop and WhatsApp. The result is a didactic sequence in which lexical units of sports and healthy living are worked based on five types of activities, with which to develop the communicative, lexical and digital competence of the students.

Key words: Oral interaction, Spanish Foreign Language, digital distance learning, lexical approach, task-based approach.

\section{Introducción}

En las dos primeras décadas del siglo XXI, la interacción oral ha ido ganando progresivamente importancia en el proceso de enseñanza-aprendizaje de lenguas extranjeras, dado su papel preponderante en la comunicación y la publicación del Marco Común Europeo de Referencia (2002). Este marco curricular supuso considerar la 
interacción oral como una destreza lingüística más, que quedó definida de la siguiente manera:

En las actividades de interacción oral, el usuario de la lengua actúa de forma alterna como hablante y oyente con uno o con más interlocutores para construir, conjuntamente, una conversación mediante la negociación de significados siguiendo el principio de cooperación. (MCER, 2002: 74)

A pesar de este gran avance, en la enseñanza de lenguas a distancia (ELaD) la interacción ha permanecido relegada en un segundo plano hasta los recientes cambios sobrevenidos con la situación de emergencia sanitaria provocada por el COVID-19, con la que la educación a distancia se ha implementado, de manera abrupta, a gran escala y en todos los niveles educativos. Mientras que la tecnología ha avanzado y la oferta de cursos de español a distancia ha aumentado a lo largo de los años, la interacción oral ha seguido igual de débil, forzando a los estudiantes a practicar por libre esta destreza (Clandfield y Hadfield, 2017; Santos Muñoz, 2011). No solo el tiempo de clase es insuficiente para desarrollar las habilidades orales, sino que, asimismo, las tareas son generalmente asignaciones fuera de clase que consisten en un relato escrito o en responder ejercicios lingüísticos, siendo ignorada por los profesores la posibilidad de asignar actividades orales como deberes (Méndez García, 2010).

De manera opuesta y simultánea, numerosas investigaciones han recopilado razones y beneficios para incluir la interacción oral en los cursos a distancia. Callagher (2008, como se citó en Clandfield y Hadfield, 2017) sugiere que es motivadora y una oportunidad de estar expuesto a una variedad de puntos de vista, de desarrollar diversas perspectivas y de colaborar en la construcción de nuevo significado. Por su parte, Méndez García (2010) defiende la importancia de asignar actividades de interacción oral fuera del aula como forma de dar atención a una habilidad que exige mucha exposición y gran práctica para ser dominada.

\section{Enfoques para la enseñanza de la interacción oral a distancia}

En este apartado presentamos dos enfoques para desarrollar la interacción oral en los cursos de ELE a distancia: el enfoque por tareas y el enfoque léxico. Para esto, delinearemos el nexo de unión entre ambas aproximaciones teóricas y las pautas para el diseño de actividades y unidades didácticas.

\subsection{El enfoque por tareas}

De los múltiples métodos comunicativos surgidos desde finales del siglo XX, el enfoque basado en la elaboración de tareas es el que mejor encaja en la ELaD, en vista de que las tareas representan situaciones reales de comunicación a las que se llega a lo largo de una unidad didáctica (Rufat Sánchez y Jiménez Calderón, 2017). Este método está diseñado para permitir que los estudiantes participen en la resolución de tareas significativas que tienen objetivos de comunicación prácticos y reales, lo que les posibilita emplear sus conocimientos para resolver los desafíos que plantea la tarea.

En la ELaD, el proceso es el mismo que en una clase presencial. La diferencia es que «la tecnología, al igual que la lengua, es [el] medio para conseguir el producto final, comunicativo y, en este caso, digital» (Herrera Jiménez y Conejo López-Lago, 2009: 11), por lo que podemos hablar de «tareas $2.0 »$, como sugieren los autores citados. Para 
llevar a cabo satisfactoriamente las actividades de interacción oral a distancia, Clandfield y Hadfield (2017) proponen una lista de verificación de preguntas para el diseño de unidades didácticas a través de tareas, que resumimos a continuación:

1. Elección 1: ¿Actividad diseñada alrededor de un tema o de un contenido lingüístico?

2. Elección 2: ¿Qué tema? ¿Qué contenido lingüístico? ¿Qué nivel?

3. Elección 3: ¿Qué tipo de actividad?

a. Personal: compartir información personal, valores y experiencias.

b. Factual: diseñar un cuestionario o un juego de búsqueda o adivinanzas basado en información objetiva.

c. Creativa: crear un «producto» (una historia, un anuncio, un proverbio o un poema).

d. Crítica: discusiones o debates basados en opiniones y argumentos lógicos.

e. Imaginativa: situaciones fantasiosas donde usar la imaginación o un juego de rol.

4. Elección 4: Estímulos (una foto; una pregunta o serie de preguntas; una frase para completar; un patrón para escribir un poema; un texto; un audio o vídeo; sentencias provocativas; un puzzle; un reto).

5. Elección 5: Patrones de interacción (respuesta abierta; respuesta guiada; secuencia de estímulos; reacción en cadena; múltiples estímulos; sala de descanso).

6. Elección 6: ¿Sincronía o asincronía?

7. Elección 7: Puesta en escena e instrucciones.

\subsubsection{El enfoque léxico}

En la década de los 90, Michael Lewis sentenció que el léxico es axial para lograr el dominio de la lengua meta, dado que sin vocabulario no tenemos «estructura fonológica, morfológica ni sintáctica; [...] es el eje del significado que se adquiere a través del contexto, y, en consecuencia, constituye la base del desarrollo de las destrezas y habilidades comunicativas en una lengua extranjera o segunda» (Rufat Sánchez y Jiménez Calderón, 2017: 48).

Esta tendencia no supone una ruptura, sino un complemento del enfoque por tareas, al que se le añaden los siguientes presupuestos (Higueras García, 2017): la enseñanza de bloques léxicos o chunks, la enseñanza contextualizada explícita e incidental del léxico y el léxico como medio para mejorar la competencia comunicativa del alumnado, relacionado con el resto de contenidos lingüísticos y funcionales. Estos principios teóricos deben utilizarse en las actividades que se diseñan para el aprendizaje del vocabulario, sin abandonar la enseñanza comunicativa por medio del enfoque por tareas.

Con este fin, pueden seguirse cuatro fases en la elaboración de una unidad didáctica que tenga como eje el componente léxico (Rufat Sánchez y Jiménez Calderón, 2017): 
1. Establecimiento de unidades léxicas en contexto.

2. Reflexión sobre las unidades léxicas y ubicación en el sistema lingüístico.

3. Prácticas guiadas a través de actividades lingüísticas y actividades comunicativas.

4. Recuperación de las unidades en producción abierta.

La aparición de la ELaD digital ha facilitado esta labor, pues es posible el acceso y desarrollo compartido de recursos de vocabulario, de acuerdo con tres tipos de enseñanza-aprendizaje del vocabulario a distancia (Pujolà Font, 2017): el ordenador como proveedor de feedback inmediato, el vocabulario implícito o explícito y la práctica con herramientas tecnológicas y con la ayuda del profesor, que es la que aquí nos interesa.

\section{La comunicación mediada por ordenador. Herramientas actuales para la interacción oral a distancia}

La comunicación mediada por ordenador (CMO) supone la interacción oral o escrita entre dos o más personas mediante ordenadores a través de Internet. Es el recurso principal que responde a las necesidades comunicativas de los aprendientes de una LE a distancia. Entre sus variadas herramientas se pueden encontrar tanto aquellas que permiten una comunicación síncrona como asíncrona. Independientemente de las que se elijan, tienen que cumplir al menos con estos cuatro requisitos para ser consideradas en una clase de idiomas (Clandfield y Hadfield, 2017): el profesor se puede comunicar públicamente vía oral o escrita con los estudiantes; estos pueden comunicarse entre sí públicamente vía oral o escrita; ambos pueden enviarse mensajes privados entre sí; ambos pueden publicar diferentes tipos de medios (imágenes, audio o vídeo).

A continuación se presentan cuatro plataformas de interacción oral que cumplen estos rasgos: Zoom, Flipgrid, Voxopop y WhatsApp. Son herramientas tecnológicas actuales (en el momento en el que se escribe este artículo), si bien con la celeridad con la que se avanza en el desarrollo de las Tecnologías de la Información y de la Comunicación, estas pueden quedarse relegadas por otras más modernas en no demasiado tiempo. No obstante, aun cuando esto suceda, seguirán respetando las cuatro condiciones estipuladas para ser aptas en la enseñanza de una segunda lengua. Esta constituye la principal razón por la que han sido elegidas, frente a la multiplicidad de medios de voz y aplicaciones de videoconferencia y de mensajería instantánea (SoundCloud, Skype, VoiceThread, etc.).

\subsection{Plataforma Zoom}

Esta videoconferencia de escritorio fue desarrollada por Eric Yuan en 2013. Permite realizar videoconferencias, chatear e impartir clases de forma fácil y rápida. Para unirse hay que recibir una invitación, normalmente por correo electrónico o desde la aplicación. Entre los rasgos más valorados de su versión gratuita, se encuentran (MundoCuentas, 2020):

1. Reuniones grupales de hasta cien participantes durante cuarenta minutos o de tiempo ilimitado en reuniones de menor tamaño. 
2. Programar reuniones. Se elige la fecha y hora y se genera un enlace que se comparte con los participantes.

3. Compartir pantalla con el resto de asistentes.

4. Pizarra virtual en la que escribir, dibujar y realizar explicaciones, y que puede ser compartida en pantalla con los usuarios.

5. Pestaña de chat para enviar mensajes o dudas de manera privada o al conjunto de la clase. A través de este también se pueden enviar archivos. Las conversaciones pueden ser guardadas al final de la sesión.

6. Envío de reacciones y emoticonos para pedir turno de palabra, mostrar acuerdo o desacuerdo, afirmación o negación, etc.

7. Posibilidad de crear salas pequeñas para discutir en grupo las tareas de forma privada.

8. Fondo virtual detrás del usuario grabado por la webcam, lo que ofrece una mejor presentación al resto de los participantes.

9. Administración de usuarios: expulsar, silenciar o intervenir de manera directa con el resto de los participantes. Igualmente, cualquier participante puede activarse o desactivarse el vídeo y/o audio.

10. Grabación de las reuniones, para poder reproducirlas el número de veces necesario, por ejemplo, para tomar apuntes, repasar o recordar detalles.

\subsection{Flipgrid}

Flipgrid es una red social educativa gratuita creada por Charlie Miller, Jim Leslie y Phil Soran en 2015. Permite crear debates en vídeo, dando voz y visibilidad al alumnado, tanto en Android como en iOS.

El profesor publica un tema en un grupo cerrado y los participantes contestan grabando un vídeo breve en el que manifiestan sus distintas opiniones e interactúan con sus compañeros a través de otra grabación (Student-to-Student Replies). De este modo, desarrollan su competencia lingüística al mismo tiempo que su competencia digital. Se puede añadir feedback a cada aportación. Para su funcionamiento, es necesario que el docente cree una cuenta de Educator. En el apartado Discussion se establecen los alumnos de cada clase o Grid y dentro de cada una se establecen los Topics, que son las preguntas o proyectos que el estudiantado ha de subir en formato vídeo, a las que ingresan con un código.

Flipgrid fomenta la competencia lingüística del alumnado en cualquier área y nivel educativo. En el ámbito de las lenguas extranjeras tiene tres potenciales aplicaciones prácticas (Huertas Abril, 2020). Por un lado, puede desarrollar el enfoque comunicativo, puesto que sirve para realizar descripciones o debates asíncronos. Por otro lado, se puede utilizar en el enfoque AICLE (Aprendizaje Integrado de Contenidos y Lenguas Extranjeras), para desarrollar la competencia lingüística y comunicativa del alumnado en la LE. Por último, puede implementarse en el enfoque por tareas, ya que se puede grabar un vídeo como fase final de una unidad, proyecto o curso, para asentar conocimientos y demostrar que han adquirido las competencias. 


\subsection{Voxopop}

Voxopop es un foro de voz gratuito creado y desarrollado por Dean Worth en 2006. A modo de podcast, esta herramienta permite crear grupos en los que los alumnos intervienen de forma estrictamente oral, sin vídeo.

Los docentes crean Talkgroups y envían invitaciones a los estudiantes. En ellos se señala la temática que deben discutir y las reglas. Los alumnos pueden hacer pruebas de su interacción oral y escucharlas repetidamente antes de subir la versión definitiva, que quedará registrada por orden de participación, aunque pueden responder a la intervención de otro compañero o abrir un nuevo hilo discursivo. En niveles iniciales o elementales las tareas con esta herramienta precisan el empleo de textos breves, «como es el caso de algunos actos de habla que siguen patrones lingüísticos muy definidos, p.ej., presentaciones, felicitaciones o agradecimientos, que no requieren la respuesta inmediata de un interlocutor» (Faya Cerqueiro, 2012: 44).

\subsection{WhatsApp}

WhatsApp es una aplicación de mensajería gratuita, creada por Jan Koum en 2009, que incluye texto, mensajes de voz, grabaciones de audio, envío de imágenes, vídeos y documentos a través de Internet. Ofrece la configuración de un gran grupo con todos los estudiantes y el docente. Puede utilizarse tanto como medio para plantear dudas y sugerencias como para proponer y elaborar tareas. Según Simarro Vázquez (2006), las características de su discurso, a caballo entre el género textual escrito y la oralidad, resultan oportunas en los primeros estadios de la enseñanza-aprendizaje de la interacción oral de los estudiantes, quienes progresivamente usarán la opción de enviar mensajes de audio. Esto facilitará una interacción más cercana a las conversaciones reales, a la vez que podrán escuchar el mensaje de su interlocutor tantas ocasiones necesiten y preparar con antelación su respuesta.

\section{Desarrollo de la Unidad Didáctica}

\subsection{Ficha técnica}

\begin{tabular}{|l|l|}
\hline GRUPO META & Estudiantes jóvenes y adultos de español general. \\
\hline NIVEL & A1, a mitad de curso, según el MCER (2002). \\
\hline $\begin{array}{l}\text { LENGUA MATERNA } \\
\text { DEL ESTUDIANTE }\end{array}$ & Inglés. \\
\hline $\begin{array}{l}\text { CONTEXTO DE } \\
\text { APRENDIZAJE }\end{array}$ & A distancia, combinación de sincronía y asincronía. \\
\hline DESTREZAS & $\begin{array}{l}\text { Interacción oral, comprensión escrita, comprensión oral y expresión } \\
\text { escrita. }\end{array}$ \\
\hline TEMPORALIZACIÓN & $\begin{array}{l}\text { Cinco sesiones de } 60 \text { minutos cada una a lo largo de dos semanas: } \\
\text { dos sesiones síncronas y tres asíncronas. }\end{array}$ \\
\hline SESIONES & $\begin{array}{l}\text { 1. Interacción personal. Síncrona. } \\
\text { 2. Interacción factual. Asíncrona. }\end{array}$ \\
\hline
\end{tabular}




\begin{tabular}{|c|c|}
\hline & $\begin{array}{l}\text { 3. Interacción creativa. Asíncrona. } \\
\text { 4. Interacción imaginativa. Síncrona. } \\
\text { 5. Interacción crítica. Asíncrona. }\end{array}$ \\
\hline $\begin{array}{l}\text { NÚMERO } \\
\text { ACTIVIDADES }\end{array}$ & $\begin{array}{l}\text { Trece actividades: tres en cada sesión, excepto la quinta sesión, que } \\
\text { cuenta con una única tarea final. }\end{array}$ \\
\hline $\begin{array}{l}\text { OBJETIVOS } \\
\text { DIDÁCTICOS }\end{array}$ & $\begin{array}{l}\text { Mejorar la competencia comunicativa del alumno mediante el } \\
\text { desarrollo de la destreza lingüística de la interacción oral. } \\
\text { Incrementar la competencia léxica del alumno acerca de los deportes } \\
\text { y de la vida saludable. } \\
\text { Desarrollar la competencia digital del alumno a través del empleo de } \\
\text { herramientas tecnológicas: videoconferencias y redes sociales. } \\
\text { Proponer que es posible incluir y trabajar la interacción oral } \\
\text { mediante tareas asíncronas fuera del aula. } \\
\text { Fomentar la interacción en el aula y el aprendizaje cooperativo. }\end{array}$ \\
\hline $\begin{array}{l}\text { CONTENIDOS } \\
\text { LINGÜÍSTICOS }\end{array}$ & $\begin{array}{l}\text { Presente de indicativo. Verbos regulares e irregulares. } \\
\text { Cuantificadores focales o presuposicionales. } \\
\text { Expresar gustos e intereses. } \\
\text { Dar información. } \\
\text { Expresar hábitos y frecuencia. } \\
\text { Expresar consejos. } \\
\text { Nociones generales del tiempo: los días de la semana y la } \\
\text { frecuencia. } \\
\text { Nociones específicas: los deportes, sus materiales y reglas, y la vida } \\
\text { saludable. }\end{array}$ \\
\hline DINÁMICAS & En gran grupo, en parejas e individual. \\
\hline $\begin{array}{l}\text { PLATAFORMAS } \\
\text { TECNOLÓGICAS } \\
\text { MATERIALES }\end{array}$ & $\begin{array}{l}\text { Zoom, Flipgrid, WhatsApp y Youtube. } \\
\text { Diccionarios bilingües en línea: Wordreference, Reverso, Linguee o } \\
\text { Diccionario Pons. } \\
\text { Imágenes de los materiales de los deportes y de personajes animados } \\
\text { que han decidido acudir a un entrenador personal. } \\
\text { Test sobre los hábitos de vida saludables. } \\
\text { Cuaderno personal del estudiante, analógico o digital, según } \\
\text { prefiera. }\end{array}$ \\
\hline EVALUACIÓN & $\begin{array}{l}\text { Sesiones síncronas: rúbrica de evaluación y tickets de salida } \\
\text { (Campamento Norte, 2021). } \\
\text { Sesiones asíncronas: rúbrica de evaluación y diana de evaluación } \\
\text { (Barcala Ruiz, 2021). } \\
\text { Ficha de autoevaluación al finalizar la UD. }\end{array}$ \\
\hline
\end{tabular}

Tabla 1. Ficha técnica de la Unidad Didáctica 


\subsection{Contexto de enseñanza-aprendizaje y metodología}

Esta propuesta didáctica está dirigida a un grupo heterogéneo de estudiantes de español general de nivel A1, según los parámetros del MCER (2002), tanto para jóvenes como para adultos. La lengua materna de estos es el inglés, en un contexto de enseñanza formal, a distancia y digital, en una academia privada de idiomas. Puede ser aplicada tanto en una situación de inmersión lingüística en España como con aprendientes que se encuentran en otros puntos geográficos, o con una mezcla de ambos. Ha sido diseñada para un grupo reducido de entre 8 estudiantes como mínimo y 10 como máximo, en la modalidad de enseñanza que combina la sincronía y la asincronía remotas.

La metodología empleada se basa en una propuesta ecléctica, considerando el alcance que ha obtenido el componente léxico y el vigor de la competencia comunicativa como meta de aprendizaje. Por un lado, tiene en cuenta el enfoque por tareas como manera de trabajar y aprender orientada a fomentar el proceso de aprendizaje guiado a la realización de una tarea final. Por otro lado, el enfoque léxico, basado en el vocabulario como eje del aprendizaje de la L2. Esta conjunción ya ha sido defendida por Cando Guanoluisa y Guanoquiza-Iza (2016) y Rufat Sánchez y Jiménez Calderón (2017).

La finalidad es desarrollar la competencia comunicativa de los alumnos, poniendo el foco en la destreza oral, especialmente en la interacción, junto con el aprendizaje del vocabulario. Así, llevamos al aula situaciones comunicativas reales y actividades significativas para los alumnos, tanto por medio de tareas individuales como en parejas y en gran grupo. El profesor será un mediador del proceso, encargado de resolver dudas, facilitar los contenidos y proveer retroalimentación.

Por ello, con el afán de potenciar el dinamismo de la clase, hemos creado actividades que siguen los cinco tipos de interacción que distinguían Clandfield y Hadfield (2017), cada tipo para cada sesión: personal, factual, creativa, crítica e imaginativa. Como material introductorio, partimos siempre de un estímulo para provocar el inicio de la conversación: una foto, una pregunta o una serie de preguntas, un audio o un vídeo. De las cinco sesiones, dos de ellas se llevarán a cabo mediante comunicación oral síncrona, con la videoconferencia de escritorio Zoom, y las otras tres serán tareas orales fuera del aula que se elaborarán por medio de herramientas de interacción asíncrona: Flipgrid y Voxopop. La aplicación de mensajería WhatsApp se reserva para adjudicar las tareas asíncronas, las instrucciones y la resolución de dudas, a través de grabaciones de audio.

Los motivos de optar por Voxopop como medio de grabar los audios de las tareas, y no hacerlo directamente con WhatsApp, son: es un foro que el profesor puede configurar con acceso restringido, los mensajes quedan grabados y organizados por grupos de discusión y las entregas no son manipulables por el resto de participantes, a diferencia de la segunda herramienta. Por otra parte, los porqués de optar por WhatsApp como vía de comunicación son su popularidad, instantaneidad y fácil accesibilidad a través de un smartphone.

La propuesta está planificada para su desarrollo a lo largo de dos semanas en cinco sesiones de 60 minutos cada una. Está concebida para ser aplicada a mitad del nivel A1, en el segundo cuatrimestre de un curso extensivo de septiembre a junio. Por lo tanto, son estudiantes que ya han compartido clases durante todo el primer cuatrimestre. Los lunes, los alumnos recibirán un enlace de la reunión de Zoom, en la que se traspasará 
toda la actividad docente propia de un aula presencial a una enseñanza a distancia. E1 resto de días, los alumnos tendrán que entregar las tareas asíncronas a través de las plataformas correspondientes. El tiempo recomendado para completar las tres actividades de cada sesión asíncrona es de 60 minutos, como una clase síncrona corriente, pero el producto que han de entregar (un audio o un vídeo), no ha de exceder los cuatro minutos de duración. La fecha límite para su entrega serán los días señalados para cada sesión asíncrona $\mathrm{y}$, hasta el día siguiente, para escuchar o ver los materiales del resto de compañeros y dejarles un comentario.

\subsection{Evaluación y seguimiento}

Durante el discurrir de la unidad didáctica tendrá lugar el seguimiento y la evaluación de la producción de los estudiantes, tanto durante el transcurso de la sesión como antes de su finalización (sesiones síncronas) o después (sesiones asíncronas).

En las sesiones síncronas, el profesor irá valorando la producción de los estudiantes al mismo tiempo que esta se efectúa, para lo que recomendamos utilizar una rúbrica de evaluación, con los criterios que el docente considere. Al final de la sesión, en los últimos diez minutos, hará una síntesis de la clase y expondrá los aciertos y deficiencias de la interacción oral de los alumnos. Anotará en la pizarra virtual una serie de oraciones dichas por los estudiantes y les pedirá que identifiquen cuáles son correctas y cuáles no y el porqué. Para concluir, utilizará la técnica de los tickets de salida, siguiendo la propuesta de Torres Ríos, López Tapia y Ruiz Torres (2021), para revisar lo aprendido durante la clase y el funcionamiento de las actividades. Si no muestran el ticket, no pueden abandonar la videoconferencia.

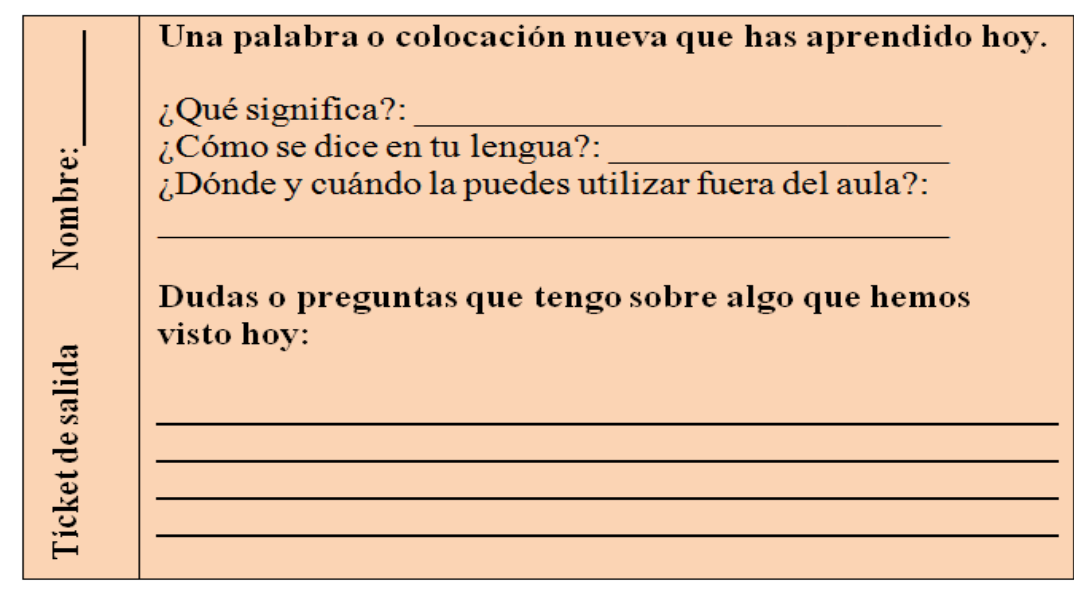

Imagen 1. Muestra de los tickets de salida, basados en Campamento Norte (2021)

En las sesiones asíncronas, el docente irá dejando comentarios, pero será, una vez expirado el plazo de entrega, cuando escuchará todas las grabaciones y, a partir de una rúbrica de evaluación, ofrecerá retroalimentación con orientaciones y correcciones. Esta la realizará creando una grabación de audio o de vídeo en la misma plataforma, comentando los diferentes aspectos de la interacción.

De manera paralela, los alumnos llevarán a cabo su autoevaluación de la sesión mediante la diana de evaluación creada por Barcala Ruiz para el curso Aprender en entornos hibridos (Instituto Cervantes, 2021). 


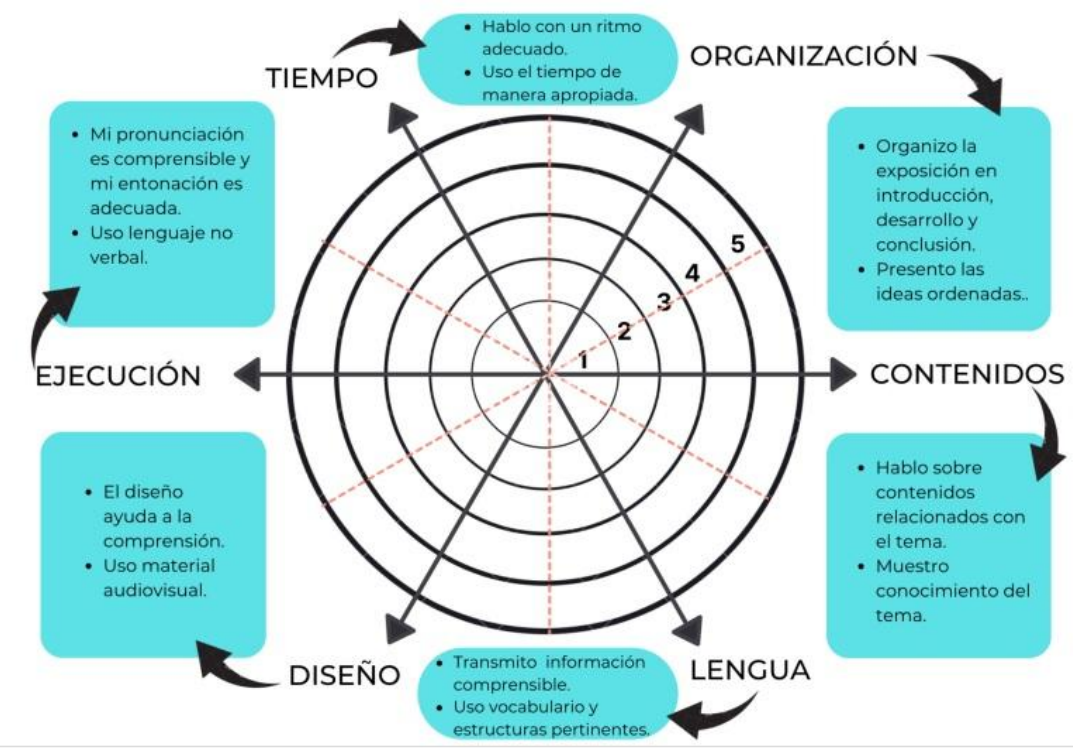

Imagen 2. Diana de evaluación de M. Barcala Ruiz (2021)

Por último, tras la quinta sesión, los alumnos contarán con una ficha de autoevaluación para comprobar los contenidos y los objetivos cumplidos de la unidad didáctica.

\section{Descripción de la secuencia didáctica}

Esta propuesta tiene como tema los deportes y la vida saludable. Cuenta con un total de trece actividades, distribuidas en cinco sesiones. Cada sesión está destinada a desarrollar un tipo de interacción, siendo las cuatro primeras sesiones posibilitadoras para la consecución de la tarea final. Los contenidos que se explotan están recogidos en el Plan Curricular del Instituto Cervantes. Niveles A1-A2 (2006).

\subsection{Sesión 1. Interacción personal. Síncrona}

\section{Actividad 1. Todo salto tiene riesgo (20 minutos)}

Comenzamos con la proyección de una imagen, dos personas haciendo paracaidismo, y con unas preguntas a modo de calentamiento, que han de responder en gran grupo, con lo que se activan los conocimientos previos de los alumnos y se les estimula a interactuar oralmente: «¿Qué deporte extremo se refleja?», «¿Qué otros conocéis?». A partir de sus respuestas, elaboramos un mapa mental de los deportes extremos, a través de la pizarra interactiva de Zoom, siempre en forma de colocaciones. 
1. TODO SALTO TIENE RIESGO. Observamos la imagen. ¿Qué deporte extremo se refleja? ¿Qué otros conocéis?

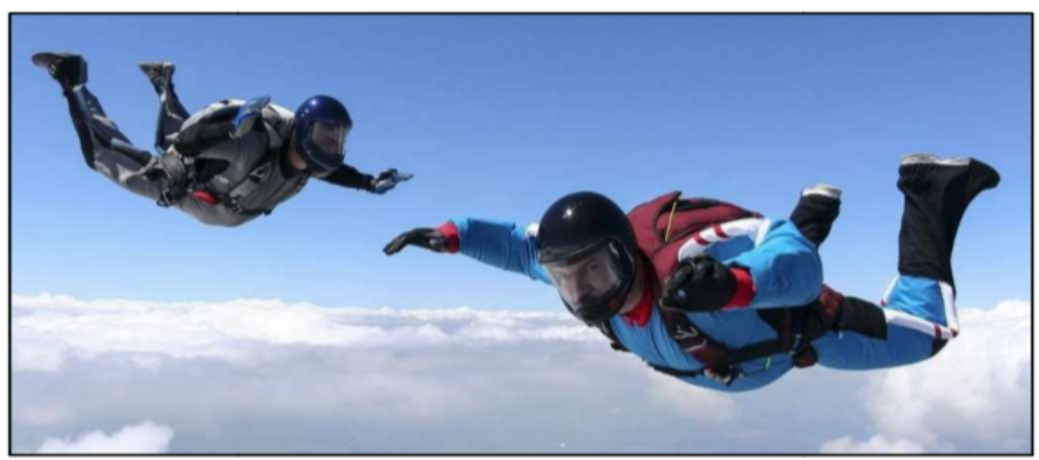

Nota. Extraída de "La trágica muerte de un paracaidista en demostración de salto", por Lempira, 2019, El Periódico.

¿Os gustan los deportes extremos? ¿Por qué?

\begin{tabular}{|cc|}
\hline Gustar + sustantivo & Gustar + infinitivo \\
& \\
$-(\mathrm{No})$ Me gusta el paracaidismo. & $-(\mathrm{No})$ Me gusta hacer paracaidismo. \\
$-(\mathrm{No})$ Me gustan los deportes extremos. & $-(\mathrm{No})$ Me gusta bucear. \\
\hline
\end{tabular}

Imagen 3. Actividad 1 de la sesión 1

A continuación, empezamos con la interacción personal: les preguntamos si les gustan los deportes extremos y por qué y si practican alguno de los que han mencionado. Para ello, se expondrá la explicación de la función comunicativa de la expresión de gustos e intereses y de la gramática necesaria, acompañadas de rondas de ejemplos. En el caso de que sean contenidos ya estudiados en unidades didácticas anteriores a lo largo del curso, se hará simplemente una revisión a partir de varios ejemplos.

\section{Actividad 2. Nos llueven las ideas (15 minutos)}

Tras el estímulo, seguimos fomentando la interacción oral, esta vez preguntándoles qué deportes comunes conocen. De nuevo, mediante una lluvia de ideas, el profesor elabora con la pizarra interactiva un mapa mental de los deportes, en forma de colocaciones. 
2. NOS LLUEVEN LAS IDEAS. ¿Qué deportes conocéis? Hacemos una lluvia de ideas.

\begin{tabular}{|l|c|c}
\hline \multicolumn{3}{c}{ LOS DEPORTES } \\
\hline \multicolumn{1}{c}{ Jugar A... } & Hacer + sustantivo & - \\
Yo juego a fútbol. & Yo hago yoga. & Yo patino. \\
Tú juegas a tenis. & Tú haces karate. & Tú boxeas. \\
É1/ ella juega a baloncesto. & É1/ ella hace surf. & É1/ ella esquía. \\
Nosotros jugamos a & Nosotros hacemos atletismo. & Nosotros corremos. \\
balonmano. & Vosotros hacéis ciclismo. \\
Vosotros jugáis a béisbol. & Ellos/ellas hacen gimnasia. & Ellos/ellas nadan. \\
Ellos/ellas juegan a rugby. & & \\
& &
\end{tabular}

Imagen 4. Actividad 2 de la sesión 1

\section{Actividad 3. ¿Le doy un «me gusta»? (15 minutos)}

Para concluir, preguntamos a los estudiantes cuáles de los deportes que hemos reunido en la actividad 2 les gustan y cuáles no. Sus respuestas siempre han de estar razonadas brevemente. El resto de compañeros han de estar atentos a las intervenciones de los demás, porque tendrán que expresar acuerdo o desacuerdo con las opiniones de sus pares. De esta forma, el aprendizaje de la sesión es acumulativo, puesto que en esta última actividad han de emplear los contenidos léxicos, gramaticales y funcionales vistos en los dos primeros ejercicios, así como incluir otro contenido nuevo: los cuantificadores focales o presuposicionales que expresan acuerdo o desacuerdo.

\footnotetext{
3. ¿LE DOY UN "ME GUSTA"? De los deportes que acabamos de ver, ¿cuál os gusta?, ¿cuál no?, ¿por qué? Conversáis entre vosotros y expresáis acuerdo o desacuerdo con vuestros compañeros.
}

\begin{tabular}{|c|c|c|}
\hline Para comunicar & & \\
\hline $\begin{array}{l}\text { - Me gusta el fútbol. } \\
\text { - A mí también. }\end{array}$ & $\begin{array}{l}\text { - Me gusta el fútbol - No me gusta el fútbol. } \\
\text { - A mí no. }\end{array}$ & $\begin{array}{l}\text { - No me gusta el fútbol. } \\
\text { - A mí sí. }\end{array}$ \\
\hline
\end{tabular}

Imagen 5. Actividad 3 de la sesión 1

\subsection{Sesión 2. Interacción factual. Asíncrona}

\section{Actividad 1. Hacer la pelota (10 minutos)}

Los estudiantes tendrán que observar la imagen que les ha sido enviada por WhatsApp: materiales y objetos de la mayoría de los deportes de la sesión anterior. De manera autónoma, han de averiguar cómo se llama cada uno de los utensilios y agruparlos según el deporte al que pertenezcan. Les instamos a que realicen búsquedas en un diccionario, monolingüe o bilingüe, siendo este último quizá más recomendado para un 


\section{Actividad 3. Solo lo sabrás si escuchas con atención (20 minutos)}

Para terminar, los estudiantes tendrán que escuchar, por lo menos, cuatro de los audios de sus compañeros y adivinar de qué deporte hablan. Sus respuestas tendrán que ser grabadas en otro audio en respuesta a cada uno (dos minutos como máximo) y tendrán que ser razonadas. De esta forma, el aprendizaje sigue siendo progresivo, dado que en esta sesión han empleado los contenidos vistos en la primera clase.

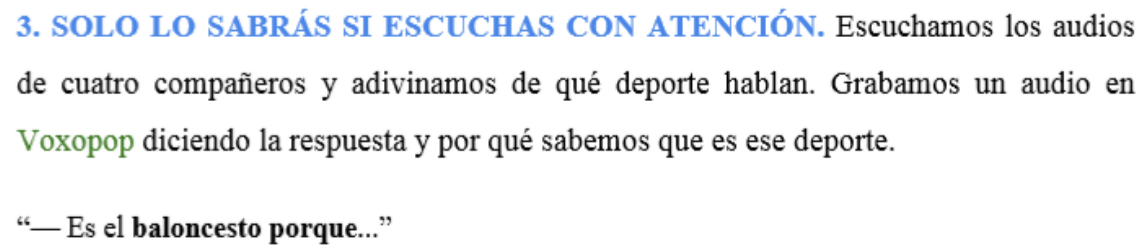

Tiempo máximo del audio: 2 minutos. Tiempo recomendado para realizar la actividad: 20 minutos. Imagen 8. Actividad 3 de la sesión 2

\subsection{Sesión 3. Interacción creativa. Asíncrona}

\section{Actividad 1. Mirar sin ver es como oír sin escuchar (10 minutos)}

Los estudiantes tendrán que visualizar el vídeo que les ha sido enviado por WhatsApp: «Hábitos saludables en la alimentación» (2016) de Tío Spanish: aprender español online. De manera independiente, habrán de anotar en su cuaderno el vocabulario que aparece en el vídeo y les insistiremos en que han de fijarse en las formas que el protagonista utiliza para dar consejos y hábitos saludables en la alimentación. De este modo, su primer contacto con estos contenidos léxicos y funcionales es inductivo.

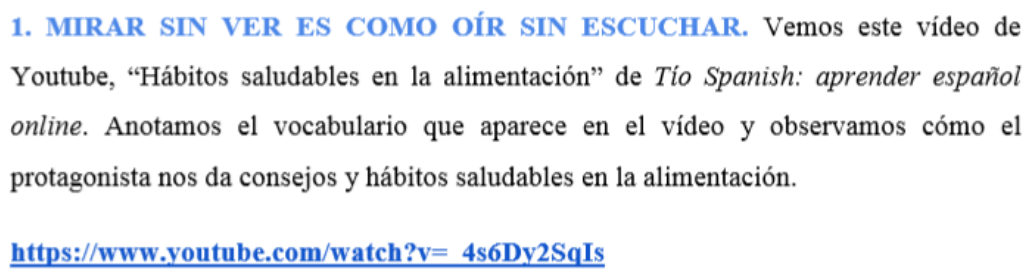

\section{Actividad 2. Bueno es aconsejar (25 minutos)}

Después de haber obtenido los contenidos lingüísticos necesarios, tendrán que grabar un audio en Voxopop, en forma de podcast, para el programa de radio "Envejecer con salud" (cuatro minutos como máximo). Tendrán que ofrecer a los oyentes consejos y hábitos de salud para los mayores de 50 años, tomando como modelo el vídeo anterior. Por ello, será indispensable que utilicen el léxico y la gramática de las sesiones previas. 


\begin{abstract}
2. BUENO ES ACONSEJAR. Vamos a nuestro grupo de Voxopop. Siguiendo el ejemplo de Tío Spanish, creamos una grabación para el programa de radio "Envejecer con salud", en el que hablamos de consejos y hábitos de salud para personas mayores de 50 años.

Recuerda: utilizamos también el léxico y la gramática de las sesiones anteriores.
\end{abstract}

Tiempo máximo del audio: 2 - 3 minutos.

Imagen 10. Actividad 2 de la sesión 3

\title{
Actividad 3. Ganando seguidores (25 minutos)
}

Para terminar esta tercera sesión, los estudiantes tendrán que escuchar por lo menos cuatro de los audios de sus compañeros y dejarles un comentario expresando si les gustan o no sus consejos, de manera argumentada. Sus respuestas tendrán que ser grabadas en otro audio en respuesta a cada uno (dos minutos como máximo). Así pues, en esta sesión han seguido sirviéndose de los contenidos vistos en las dos primeras clases, por lo que el aprendizaje continúa siendo progresivo y acumulativo.

3. GANANDO SEGUIDORES. Escuchamos las grabaciones de cuatro compañeros y

les dejamos un comentario diciendo si nos gustan o no sus consejos.

Tiempo máximo del audio: 2 minutos.

Imagen 11. Actividad 3 de la sesión 3

\subsection{Sesión 4. Interacción imaginativa. Síncrona}

\section{Actividad 1. Cuerpo sano, mente sana (15 minutos)}

Empezamos con el estímulo, un par de preguntas sobre los hábitos de los estudiantes, que tendrán que responder en gran grupo: «¿Creéis que lleváis una vida sana?» y «¿Qué es para vosotros una vida sana?». Posteriormente, completarán un test sobre sus hábitos, puntuándolos del 1 al 5 . En parejas, compararán sus respuestas e interactuarán oralmente.

Para trabajar en parejas, crearemos salas privadas de Zoom, cuya configuración permite distribuir a los alumnos de manera aleatoria por grupos de dos o elegir qué alumnos trabajarán conjuntamente en cada una de las salas. 
1. CUERPO SANO, MENTE SANA. Conversamos y reflexionamos juntos:

a) ¿Creéis que lleváis una vida sana?

b) ¿Qué es para vosotros una persona sana?

c) Ahora vamos a puntuar nuestros hábitos del 1 (nunca) al 5 (muy frecuente) y comparamos los resultados con los de nuestros compañeros. ¿Quién es más sano?

1. Hago deporte con frecuencia

2. Duermo 8 horas al día

3. Como sano todos o casi todos los días

4. Paso tiempo con mis amigos y con mi familia

5. Sigo tratamientos para la cara y el cuerpo

6. Tomo los medicamentos que me recomienda el médico

“-Yo hago deporte con frecuencia: un 5. ¿Y tú?"

“-Yo también / yo no..."

Imagen 12. Actividad 1 de la sesión 4

\section{Actividad 2. Soy entrenador personal (20 minutos)}

Les mostramos a los estudiantes una fotografía con varios personajes animados que han acudido a un entrenador personal por voluntad propia: Homer Simpson, Peter Griffin, Mulan, etc. Los alumnos tienen que imaginar que son sus entrenadores personales. Los dividiremos en parejas y los enviaremos a salas privadas de Zoom. Entre sí tendrán que interactuar y diseñar a su personaje una planificación con alimentación saludable y deportes para cada día de la semana, por lo que vuelven a emplear los contenidos de la sesión 1. Iremos conectándonos a cada sala para comprobar que los estudiantes hablan en español y preguntarles si tienen dudas.

2. SOY ENTRENADOR PERSONAL. Observamos esta imagen. Son personajes animados que han acudido a un entrenador personal por voluntad propia. ¿Los conocéis?
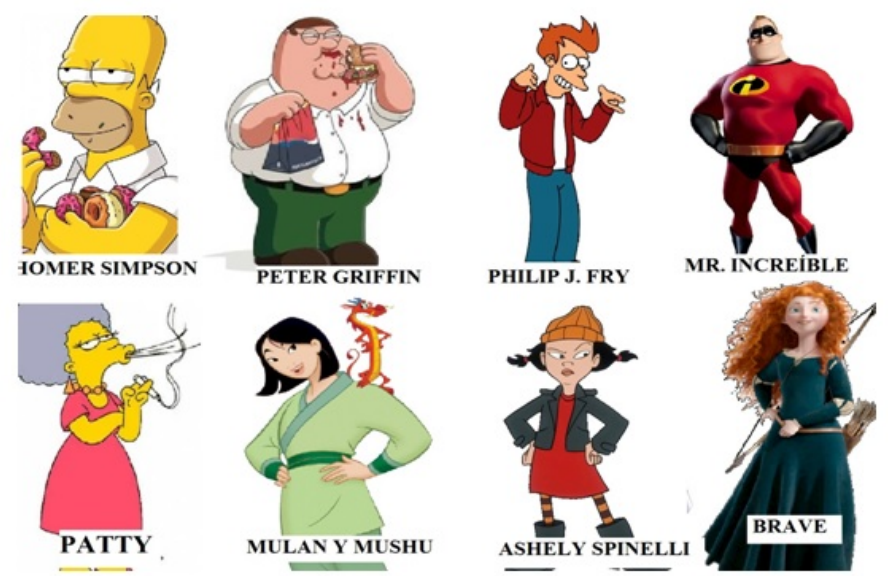


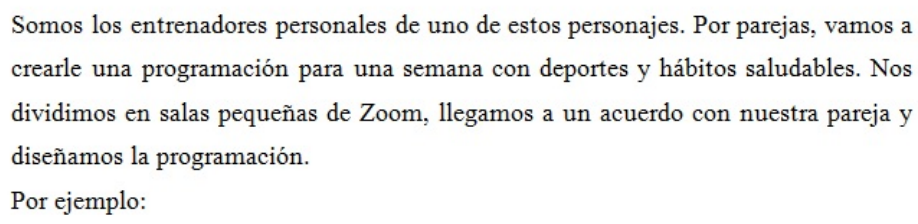

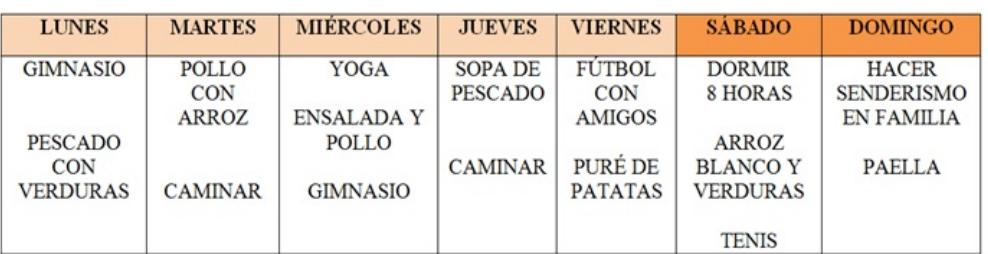

Tiempo máximo: 20 minutos

Imagen 13. Actividad 2 de la sesión 4

\section{Actividad 3. Te cuento mi plan (20 minutos)}

Los alumnos vuelven a la sesión principal de Zoom. Por turnos, cada pareja cuenta al resto de la clase qué programación han diseñado a su personaje y qué consejos le dan. Para ello, el profesor habrá explicado o repasado previamente, dependiendo del caso, los días de la semana, las fórmulas para expresar frecuencia y para aconsejar. Cuando terminen, los compañeros expresarán si les gustan las planificaciones de sus compañeros, para lo cual emplearán las expresiones aprendidas en las sesiones anteriores.

3. TE CUENTO MI PLAN. Volvemos a la reunión principal de Zoom. Cada pareja cuenta qué consejos le da a su personaje sobre qué tiene que cambiar de su vida y la planificación que han creado.

A: Homer tiene que ir al gimnasio los lunes y los miércoles.

$B$ : Dos veces a la semana tiene que comer verduras.

A: No puede beber tantas cervezas.

\begin{tabular}{|c|c|}
\hline Hablar de los días y de la frecuencia & Aconsejar \\
\hline $\begin{array}{l}\text { De lunes a viernes voy al gimnasio. } \\
\text { Los viernes juegas a fútbol. }\end{array}$ & (No) Tener que + infinitivo \\
\hline $\begin{array}{l}\text { Entre semana Peter come sano. } \\
\text { Los fines de semana dormimos } 8 \text { horas. } \\
\text { Algunos días hacéis yoga. }\end{array}$ & $\begin{array}{l}\text { - Tienes que comer sano. } \\
\text { - Tenemos que hacer deporte. } \\
\text { — No tenéis que fumar. }\end{array}$ \\
\hline $\begin{array}{l}\text { Una vez a la semana / Una vez al mes... } \\
\text { Dos veces a la semana / Dos veces al mes... }\end{array}$ & (No) Poder + infinitivo \\
\hline $\begin{array}{l}\text { Todos los días / Todas las tardes / Todas las noches / } \\
\text { Todos los meses / Todos los sábados } \\
\text { Por la mañana / Por la tarde / Por la noche }\end{array}$ & $\begin{array}{l}\text { - Puedes comer paella una vez a la } \\
\text { semana. } \\
\text { — Podemos beber cerveza los fines de } \\
\text { semana. } \\
\text { — No podéis comer pizza todos los días. }\end{array}$ \\
\hline
\end{tabular}

Imagen 14. Actividad 3 de la sesión 4 


\subsection{Sesión 5. Interacción crítica. Asíncrona}

\section{Tarea final. De salud y dinero, el primero (60 minutos)}

Los alumnos realizan el proyecto final: un vídeo en Flipgrid (máximo cuatro minutos). Los dividiremos en parejas: uno será un deportista y otro un periodista. Ahora bien, el vídeo lo graban de manera individual. Primero, el periodista subirá un vídeo haciéndole preguntas al deportista sobre sus hábitos y qué consejos le da él a la gente para llevar una vida sana. Tras esto, el otro compañero visualizará el vídeo y grabará otro, como si fuera un deportista, respondiendo a las preguntas. Ambos han de utilizar los contenidos léxicos, gramaticales y funcionales de las primeras cuatro sesiones. Cuando terminen, tendrán que ver los vídeos de sus compañeros y dejar un comentario valorándolos y votando por el mejor deportista de la clase: el que mejor habla y el más sano.

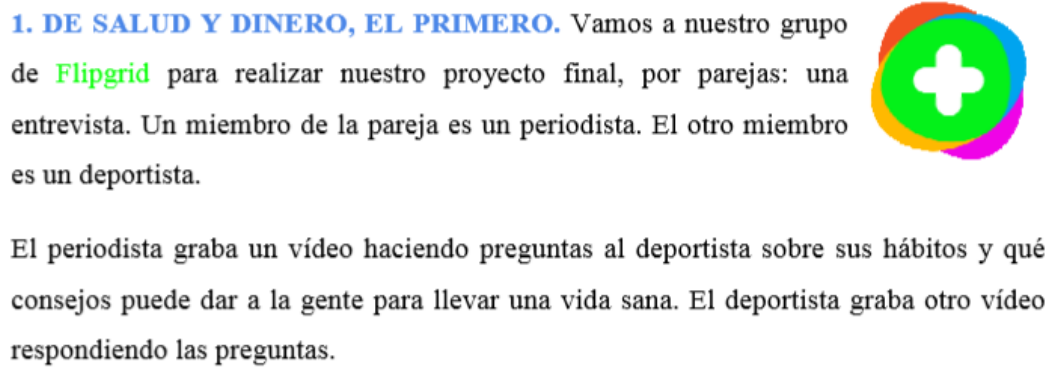

Imagen 15. Tarea final de la sesión 5

\section{Consejos y consideraciones para la puesta en práctica}

La interacción oral en un curso de idiomas a distancia puede resultar provechosa y satisfactoria tanto para los alumnos como para el profesor, pero, al mismo tiempo, constituye un reto, puesto que no siempre se coincide en tiempo y espacio con los estudiantes. Por estos motivos, han de tenerse en cuenta algunas consideraciones, al inicio y durante el curso, para lograr el éxito deseado.

Primeramente, los estudiantes han de familiarizarse con las plataformas tecnológicas que se emplean a lo largo de la unidad didáctica. A pesar de que son herramientas que probablemente ya conozcan y de que vivimos en una sociedad digitalizada, es necesario explicarles con exactitud cómo esperamos que las utilicen durante la asignatura.

Esta es una propuesta didáctica pensada para ser aplicada a mitad del curso, por lo que en ese momento los alumnos ya habrán utilizado en bastantes ocasiones estas plataformas. Sin embargo, creemos conveniente ofrecer algunos consejos para profesores interesados en ponerla en funcionamiento al principio de curso. Lo más importante es que los aprendientes sepan cómo acceder a la plataforma, dónde encontrar las tareas, dónde y cómo publicar sus respuestas y cómo responderse en línea unos a otros. Para ello, proponemos dos formas de proceder. Una puede ser crear un documento con capturas de pantalla que explique paso a paso el funcionamiento de la plataforma y enviárselo por correo electrónico o por WhatsApp. La otra puede ser 
grabar un screencast o videografía de nuestro monitor en el que les mostramos la interfaz de la aplicación y les narramos paso a paso cómo moverse por ella.

Una vez aclarados los aspectos logísticos, vamos a proporcionar algunas sugerencias para que durante el curso el docente ayude a generar y mantener la interacción de los estudiantes en las actividades que hemos diseñado, por si se encontrara con un grupo más reacio a participar, aunque son útiles para todos los grupos y recomendamos emplearlas de manera sistemática.

En primer lugar, aconsejamos al profesor que al principio de la unidad didáctica participe pronto, frecuentemente y de la forma que quiere que los estudiantes actúen y participen, ya que, al comienzo, la mayoría de los participantes esperarán de él alguna indicación de cómo interactuar. Después, cuando el grupo se adapte a la mecánica y participe entre sí, el profesor podrá reducir su participación. En relación con esto, a medida que los estudiantes publiquen sus respuestas, hay que demostrarles que las estamos escuchando o viendo y que nos interesan. Los estudiantes no sabrán que hemos visto su tarea si no dejamos un comentario, aunque sea un «me gusta».

En segundo lugar, es muy útil establecer plazos para las tareas asíncronas, puesto que ayudan a mantener el estímulo de seguir en el curso. Es una forma de que todos sepan cuándo deben hacer su parte. Ahora bien, un problema puede ser que los participantes dejen su intervención para el último momento, por lo que la interacción con los demás compañeros no será posible. Por esto, han de señalarse en cada sesión asíncrona dos fechas: una para que los estudiantes publiquen su propio audio / vídeo y otra para que escuchen / vean las respuestas de sus compañeros y les dejen algún comentario oral. Además, si observamos que en una actividad la participación empieza a decaer, proponemos reactivarla publicando un resumen de lo que los estudiantes han dicho hasta ese momento y acomodar la tarea para facilitar que el resto se incorpore a la discusión.

En tercer lugar, cuando finalice cada sesión tenemos que procurar que los estudiantes mantengan la participación $\mathrm{y}$, si es posible, que aumenten su interacción en las siguientes. Para conseguirlo, aconsejamos que el profesor grabe un audio o un vídeo, dependiendo del caso, anunciando que las tareas han terminado $\mathrm{y}$, sobre todo, agradeciendo a todos los alumnos su participación. Asimismo, debería hacer un resumen de lo estudiado en la sesión e incluir ideas de cada uno de los estudiantes, usando sus nombres, dado que es una técnica que potencia su autoestima y los anima a seguir esforzándose, al ver que han logrado el objetivo. Aparte, tendrá que dejar un mensaje individualizado a cada alumno evaluando a grandes rasgos su desarrollo de la sesión de manera particular.

Para concluir, en cuanto a la puesta en práctica en sí de las trece actividades que componen esta unidad didáctica, nos gustaría mencionar algunas consideraciones. Por un lado, en las sesiones síncronas ( 1 y 4$)$, recomendamos comenzar la clase presentando y explicando los objetivos y revisar el léxico y/o la gramática que van a necesitar para poner en marcha las actividades de interacción oral. Para ello, sugerimos emplear la pizarra interactiva con la que cuenta la videoconferencia Zoom o, como alternativa, un documento Word compartido. En virtud de que se trata de una clase a tiempo real y todos los participantes son visibles a través de la cámara web, es conveniente que el profesor y los alumnos introduzcan gestos, expresiones faciales o posturas que 
acompañen su discurso, como estrategias de comunicación para superar las dificultades en el proceso de comunicación oral.

Por otro lado, en las asíncronas (2, 3 y 5 ) hemos propuesto enviar los enunciados y objetivos de las tareas mediante audios de voz, por el grupo de WhatsApp y la plataforma correspondiente, para reforzar la interacción oral. Con todo, dado que se trata de un nivel A1, recomendamos que el profesor complemente la grabación con el envío por escrito del enunciado por medio de un documento compartido en Google Drive e, incluso, si lo considera necesario, la transcripción de los audios que sirven de modelo para realizar la actividad.

\section{Conclusiones}

El presente artículo ha constituido el desarrollo de una propuesta didáctica para trabajar la interacción oral síncrona y asíncrona con alumnos de ELE de nivel A1 en un entorno de enseñanza a distancia digital. Nuestro objetivo ha sido proponer que la enseñanza a distancia puede tener la misma efectividad que un curso tradicional presencial y que es posible incluir tareas de interacción oral para desarrollar la competencia comunicativa en la ELaD, como defendía Méndez García (2010). Para ello, hemos presentado la situación actual de la interacción oral en la ELaD y la eficacia de la combinación del enfoque por tareas y del enfoque léxico en el diseño de actividades de interacción oral, como propugnaban Cando Guanoluisa y Guanoquiza-Iza (2016) y Rufat Sánchez y Jiménez Calderón (2017).

Tras esto, hemos introducido nuestra propuesta didáctica, que sigue el proyecto de Clandfield y Hadfield (2017). En nuestro caso, no hemos podido pilotarla porque durante su desarrollo no éramos profesores en ejercicio. Sin embargo, deseamos llevarla a efecto próximamente en cursos futuros, aunque, mientras tanto, la ponemos a disposición para que compañeros de ELE que estén interesados puedan usarla en sus clases. Sería provechoso que compartieran con nosotros cómo ha funcionado la aplicación en su propia aula, para poder llevar a cabo un seguimiento y una evaluación de la propuesta. Esta ha sido diseñada de forma que puede ser adaptada a las características del contexto en la que se pretenda implantar, pero el profesor será el responsable último de determinar si es viable de ser aplicada con su grupo de alumnos, teniendo en cuenta la edad, la procedencia, las lenguas, los referentes socioculturales, la disponibilidad y el acceso a soportes digitales y de red de los estudiantes. También podría realizarse la misma investigación en otros contextos de aprendizaje para comparar los resultados, o bien realizar nuevas investigaciones continuando la tendencia que planteamos en este trabajo.

Consideramos que se trata de una propuesta novedosa en cuanto a que es uno de los primeros estudios que ofrece un conjunto de tareas cuyo eje es el uso de herramientas tecnológicas. Asimismo, que el enfoque por tareas se complemente con el enfoque léxico es una opción poco escogida en la elaboración de secuencias didácticas. Esto, unido al hecho de que el nivel al que va dirigida es un A1, incrementa su particularidad. 


\section{Bibliografía}

BARCAla RuIZ, María. 2021. Cómo aprender en entornos híbridos. Madrid: Centro de Formación del Instituto Cervantes en entornos híbridos.

CAMPAMENTO NORTE. 2021. Tíckets de salida. Recuperado el 04/07/21, de: https:/campamentonorte.com/cursos/tickets-de-salida/.

CANAl Tío SPANiSh: APRENDER ESPAÑOL ONLINE. 21 de noviembre de 2016. Hábitos saludables en la alimentación [Archivo de vídeo]. Youtube. Recuperado el 06/04/21, de: https://www.youtube.com/watch?v=_4s6Dy2SqIs.

CANDo Guanoluisa, Fabiola y Guanoquiza-IzA, Carlos. 2016. «Implementación de tareas orales por medio de la combinación del enfoque basado en tareas y el enfoque léxico para desarrollar la competencia oral». Revista Boletín Redipe, 5(6), 70-80.

CLANDFIELD, Lindsay y HADFIELD, Jill. 2017. Interaction Online. Creative activities for blended learning. Cambridge: Cambridge University Press.

FAYA CERQUEIRO, Fátima María. 2012. «La producción oral en lenguas extranjeras más allá del aula con el foro de voz Voxopop». Texto Livre: Linguagem e Tecnologia, 5(2), 38-47. DOI: https://doi.org/10.17851/1983-3652.5.2.38-47.

Herrera JimÉneZ, Francisco y CONEJo LÓPEZ-LAGo, Emilia. 2009. «Tareas 2.0: la dimensión digital en el aula de español lengua extranjera». Marcoele. Revista didáctica español como lengua extranjera, 9, 1-20.

Higueras GARcía, Marta. 2017. «Logros y retos de la enseñanza del léxico». En F. Herrera (ed.), Enseñar léxico en el aula de español. Barcelona: Difusión, 13-23.

HUERTAS ABRIL, Cristina. 2020. «Flipgrid: una herramienta para darle voz al alumnado». Observatorio de tecnología educativa, 31, 3-10.

InSTITUTO CERVANTES. 2002. Marco común europeo para las lenguas: aprendizaje, enseñanza, evaluación. Madrid: Anaya. [Traducción al español de Common European Framework of Reference for Languages: Learning, Teaching, Assessment. Strasbourg: Council of Europe, 2001]. Recuperado el 04/07/21, de: https://cvc.cervantes.es/ensenanza/biblioteca_ele/marco/cvc_mer.pdf.

Instituto Cervantes. 2006. Plan Curricular del Instituto Cervantes. Niveles de referencia para el español. Madrid: Instituto Cervantes.

MÉNDEZ GARCÍA, Elba. 2010. «How to set up oral homework. A case of limited technology». English Teaching Forum, 3, 10-19.

MundoCuENTAS. 23 de septiembre de 2020. Zoom: qué es, características y cuáles son sus ventajas $y$ desventajas. Recuperado el 05/05/21, de: https://www.mundocuentas.com/zoom/.

PUJOLÀ FONT, Joan-Tomàs. 2017. «El uso de las tecnologías para la enseñanza y aprendizaje del léxico». En F. Herrera (ed.), Enseñar léxico en el aula de español. Barcelona: Difusión, 187-195.

Rufat SÁnChez, Anna y JimÉnEz CALDERÓn, Francisco. 2017. «Aplicaciones de enfoques léxicos a la enseñanza comunicativa». En F. Herrera (ed.), Enseñar léxico en el aula de español. Barcelona: Difusión, 47-55. 
SANTOS MUÑOZ, Arantxa. 2011. «La interacción oral en los cursos de español en línea: análisis de una experiencia de aula». En C. González, A.C. Santana y E. Álvarez (eds.), La Red y sus aplicaciones en la enseñanza-aprendizaje del español como lengua extranjera. Valladolid: Asociación para la Enseñanza del Español como Lengua Extranjera, 487-496.

SiMARRO VÁZQUEZ, María. 2016. «Integración de WhatsApp en la enseñanza de español como segunda lengua. Propuesta de b-learning». En A.G Ravelo, S. T. Pérez, J. Bernardino (eds.) et al., III Jornadas Iberoamericanas de Innovación Educativa en el ámbito de las TIC. Las Palmas de Gran Canaria: Universidad de Las Palmas de Gran Canaria, 195-200.

TORRES Ríos, Lola, LÓPEZ TAPIA, Francisco Javier y RUIZ TORRES, Vanessa. 2021. «La evaluación en el aula de lenguas. La innovación pendiente». eHIZPIDE, 98. 